\title{
Pharmacy Technician Workload and Human Resources Requirements at MOH Hospitals during Nine years Mass Gathering Hajj (2006-2014) in Al-Medina Region, Saudi Arabia
}

\author{
Yousef Ahmed Alomi*1, Khairat Alhennawi², Nizar Khayayt ${ }^{3}$ \\ ${ }^{1}$ The Past General Manager of General Administration of Pharmaceutical Care and \\ Head, National Clinical pharmacy, and pharmacy practice and Pharmacy $R \& D$ Administration, \\ Ministry of Health, Riyadh, KSA. \\ ${ }^{2}$ Clinical pharmacy staff, General Administration of Pharmaceutical Care, Ministry of Health, Riyadh, KSA. \\ ${ }^{3}$ Medication Safety Officer General Administration of Pharmaceutical care, Makkah Region, \\ Ministry of Health, Riyadh, KSA.
}

Received: 13 August 2017;
Accepted: 28 September 2017
*Correspondence to:
Dr. Yousef Ahmed Alomi,

The Past General Manager of General Administration of Pharmaceutical Care

Head, National Clinical pharmacy, and pharmacy practice

Head, Pharmacy $R \&$ D Administration Ministry of Health, P.O.BOX 100, Riyadh 11392, Riyadh, Saudi Arabia.

Email:yalomi@gmail.com

Copyright: (C) the author(s),publisher and licensee Indian Academy of Pharmacists. This is an openaccess article distributed under the terms of the Creative Commons Attribution Non-Commercial License, which permits unrestricted non-commercial use, distribution, and reproduction in any medium, provided the original work is properly cited.

Publishing Partner : EManuscript [www.emanuscript.in]

\begin{abstract}
Objective: To explore the pharmacy technician workload analysis and workforce requirements at Ministry of Health Hospitals during mass gathering Hajj nine years (2006-2014) in Al-Medina Region, Saudi Arabia. Methods: It is a retrospective of nine years (2006-2014) of hospital pharmacy technician workload during mass gathering Hajj period. The duration of workload collection was 15-30 days each year. The pharmacists provide pharmaceutical to all patients either Pilgrim or not Pilgrim at Medina region. The workforce requirements calculated based on $\mathrm{MOH}$ workforce standards per bed and the workload drives as central pharmacy technician services, patient specific pharmacy technician activities, and general administration specific pharmacy technician activities. Results: The total number of Pilgrims $(1,952,817-3,161,573)$ with average $(2,445,208)$. The total number of prescriptions was $(22,278-133,107)$ with an average of $(78,955)$. It represented $(1.07-5.02 \%)$ with an average $(3.11 \%)$ of all pilgrims. The total average number of pharmacy technician needed in Al-Madina was (69.2 FTE) per hospital. It divvied into (3.21FTE) for inpatient services per hospital, (11.48 FTE) for Emergency services per hospital, and (54.51FTE) for Ambulatory care services per hospital. The average number of pharmacy technician calculated per hospital was (38.47 FTE), while the mean number pharmacy technician needed to base on workload for all services was (69.20 FTE) per hospital. Conclusion: The pharmacy technician workforce's analysis showed high demand during mass gathering Hajj over past several years despite clinical pharmacy technician missed. Aiming to increase workforce of pharmacy technician is potential to improve pharmacy services during mass gathering Hajj period in Al-Madina, Saudi Arabia.
\end{abstract}

Keyword: Pharmacy Technician, Workload, Workforces, Mass Gathering, Hajj, Al-Medina, Ministry of Health, Saudi Arabia

\section{INTRODUCTION}

Al-Madina Almunawara is one of the holy cities in Islam. Some pilgrims visited either before went to Makka or after finished the Hajj performance. The mass gathering is the attendance or participation of a vast number of people (usually more than 1000 people) in an event. ${ }^{[1]}$ The hajj conferee considered the biggest mass gathering event 
in the world. The Ministry of Health in the Kingdom of Saudi Arabia expanded the medical services over the years with some hospitals or primary care centers. ${ }^{[2]}$ The expansion needs several things including health care Human Resources. The physicians, pharmacists, and nurses included with additional to assistant medical professionals for instance assistant nurses, assistant radiology, and assistant pharmacists or pharmacy technicians. Also, the huge numbers of mass gathering hajj demand very high numbers of medical professionals. Several studies done about health related issues during Hajj; included the patterns of diseases, the effect of pre-vaccination, the patient satisfaction of ambulatory care. ${ }^{[3-7]}$ It is hard to find locally or Gulf area or Middle East countries and overall the world investigations of workforces during mass gathering events. The pharmacy technician help and support the pharmacist and clinical pharmacist with all pharmacy related performances. The pharmacy technician's description job well known in USA, Canada, and Austria with several publications while missed in Saudi Arabia or Gulf or Middle East countries. ${ }^{[8-10]}$ The pharmacy technician discipline not adequately discussed in the literature, as the term mass gathering pharmaceutical care established recently in 2016 by Alomi et al. ${ }^{[11]}$ Moreover, the authors not familiar with any investigation either locally or in the world about pharmacy technician's workforce during mass gathering events with an emphasis on Hajj period. In this study, the authors have measured the pharmacy technician workload and human resources requirements at $\mathrm{MOH}$ hospitals during nine years mass gathering Hajj (2006-2014) in Al-Medina Region.

\section{METHODS}

It is a retrospective of nine years (2006-2014) of pharmacy technician workload at hospitals during mass gathering Haji period. The duration of workload collection was 15-30 days. The pharmacists prepare the medications and pharmaceuticals for dispensing to all patients either Pilgrim or not Pilgrim at Al-Madina region. All the data derived from Ministry of Health. Health Statistical Year Books..$^{[12-20]}$ Also, there was extensive literature review search at open date periods with fifty databases included. It included the type of studies (meta-analysis, randomized controlled studies, and observational studies, books, reports etc) in the English language. The search for the term of Hajj and workforce, Hajj and workforce, Hajj and human resources or mass gathering and workforce, mass gathering and workforce, mass gathering and human resources. The search term was in the title and key words. All setting of patient care services hospitals; inpatient or ambulatory care or community services included. The search included pharmacy technician. The location of studies included Saudi Arabia as top propriety if not existed Gulf or Middle East countries included, if not found overall counties included. The twenty hospitals included in the study located in Al-Medina. ${ }^{[21-24]}$ The workforce requirements calculated based on $\mathrm{MOH}$ workforce standards per bed and the workload derived from as central pharmacy technician services, patient-specific pharmacy technician activities. Moreover, general administration specific pharmacy technician activities based on American college of clinical pharmacy society and other literature..$^{[8-10,25-27]}$ The updated hospital's demographic information and the workload calculation based on $\mathrm{MOH}$ and pharmacy administration database in Al-Madina region with considered that is an average time of pharmacy technician preparation for dispensing inpatient order was three minutes; while Ambulatory care and emergency two minutes. All calculation done used Microsoft Excel version ten.

\section{RESULTS}

There were twenty hospitals in Al-Madina region while nine hospitals only mentioned in $\mathrm{MOH}$ statistical book. The majority of them provided Adults intensive care units $20(100 \%)$, Neonatal intensive care units 20 (100\%), Emergency services 20 (100\%) Ambulatory care services $20(100 \%)$. It followed by Surgery services $20(100 \%)$, Maternity, Obstetrics, and Gynecology $20(100 \%)$, and General Pediatrics 20 (100\%). Few hospitals got accreditations from local organization CBAHI $6(30 \%)$, while only small hospitals had accreditation from international institution Joint commission 3 (15\%). Most of the hospital had an outpatient pharmacy, inpatient pharmacy and emergency followed by medication safety officer and total pharmacy quality management $20(100 \%)$ while missed patient counseling and medication reconciliation $0(0 \%)$. The most pharmacy technician activities were Prepare the medications for dispensing Inpatient, OPD, Emergency Pharmacy, Distribution of floor stock medication, and Assistant for Extemporaneous preparation 20 (100\%). Followed by Management of medicines, Pharmacy store and Documentation of Medication Safety officer reports, and assist the pharmacist in the Pharmacy Total Quality 20 $(100 \%)$. While missed Documentation of Clinical Pharmacy Services Documentation of Patient Counseling and Assistant the pharmacist in the Medication Reconciliation $0(0 \%)$. The total number of Pilgrims was $(1,980,249-3,161,573)$ with average of $(2,499,918.22)$. The average number of pilgrims per hospital was $(483,882.470)$ and $3,087.18$ pilgrims per bed over nine years. The total number of prescriptions was $(22,278-133,107)$ with an average of $(78,955)$. It represented 
Pharmacy technician workforces at Hospitals during Hajj in Al-Madina

\begin{tabular}{|c|c|c|c|c|c|c|c|c|c|c|c|c|c|c|c|c|c|c|c|c|c|c|c|c|}
\hline & 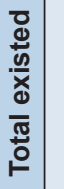 & & 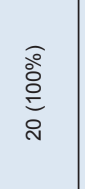 & 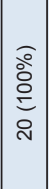 & $\begin{array}{l}\frac{0}{0} \\
\text { อ } \\
0\end{array}$ & 嗃 & $\begin{array}{l}\overline{0} \\
\text { ò } \\
\text { co } \\
\text { ò }\end{array}$ & 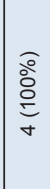 & ò & ô & $\mid \begin{array}{l}0 \\
\text { o. } \\
0\end{array}$ & $\begin{array}{l}\text { Oे } \\
\text { Oे } \\
0\end{array}$ & 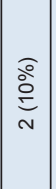 & 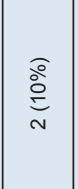 & 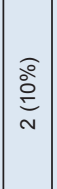 & 高 & 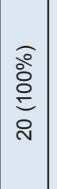 & 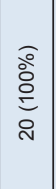 & 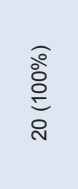 & $\mid \begin{array}{l}0 \\
\stackrel{0}{0} \\
0\end{array}$ & $\begin{array}{c}0 \\
\stackrel{\circ}{0}\end{array}$ & 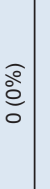 & ठ응 & $\begin{array}{l}\text { o̊̀ } \\
\circ\end{array}$ \\
\hline & 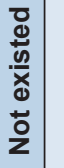 & & 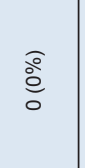 & 总 & 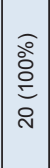 & 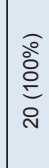 & ᄋ̊ & \begin{tabular}{|l}
$\stackrel{\circ}{\circ}$ \\
$\stackrel{0}{0}$ \\
0
\end{tabular} & 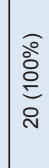 & 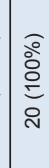 & 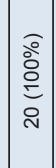 & 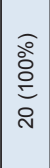 & $\begin{array}{l} \\
\stackrel{\circ}{\circ} \\
\stackrel{\circ}{o} \\
\stackrel{0}{0}\end{array}$ & $\begin{array}{l}0 \\
\stackrel{\circ}{\circ} \\
\stackrel{0}{0} \\
\infty\end{array}$ & 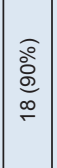 & 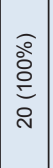 & 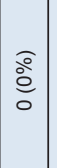 & 离 & 总 & 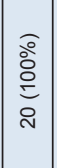 & 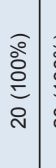 & 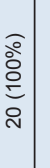 & 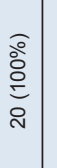 & $\begin{array}{l}\text { ō } \\
\text { ò } \\
\text { ò }\end{array}$ \\
\hline & $\begin{array}{l}8 \\
8 \\
\wedge\end{array}$ & & 0 & 0 & 0 & 0 & 0 & 0 & 0 & 0 & 0 & 0 & 0 & 0 & 0 & 0 & 0 & 0 & 0 & 0 & 0 & $\circ$ & 0 & 0 \\
\hline & 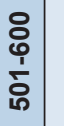 & & - & - & 0 & 0 & $r$ & $r$ & 0 & 0 & 0 & 0 & $1-$ & - & - & 0 & $r$ & $r$ & $r$ & 0 & $\circ$ & $\circ$ & 0 & 0 \\
\hline & 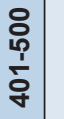 & & $r$ & $r$ & 0 & 0 & $r$ & - & 0 & 0 & 0 & $\circ$ & - & $r$ & - & 0 & $r$ & $r$ & $r$ & $\circ$ & $\circ$ & $\circ$ & $\circ$ & 0 \\
\hline & 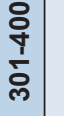 & & 0 & 0 & 0 & 0 & 0 & 0 & 0 & $\circ$ & 0 & $\circ$ & 0 & 0 & 0 & 0 & $\circ$ & 0 & 0 & $\circ$ & $\circ$ & $\circ$ & $\circ$ & 0 \\
\hline 흥 & 容 & & N & $\sim$ & 0 & 0 & $N$ & 0 & 0 & 0 & 0 & 0 & 0 & 0 & $\circ$ & 0 & $\sim$ & $\sim$ & $\sim$ & $\circ$ & 0 & $\circ$ & 0 & 0 \\
\hline 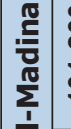 & ণัָุ & & $\nabla$ & $\sigma$ & 0 & 0 & $\sigma$ & $\sim$ & 0 & $\circ$ & 0 & 0 & 0 & 0 & 0 & 0 & $\sigma$ & $\sigma$ & $\sigma$ & 0 & 0 & $\circ$ & $\circ$ & 0 \\
\hline 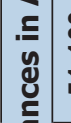 & $\frac{8}{\frac{1}{1}}$ & & $\sim$ & $\sim$ & 0 & 0 & $N$ & 0 & 0 & 0 & 0 & 0 & 0 & 0 & 0 & 0 & $N$ & N & N & 0 & 0 & 。 & 0 & 0 \\
\hline 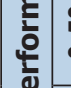 & นึి & & $\stackrel{\circ}{\circ}$ & $\stackrel{\circ}{\circ}$ & 0 & 0 & $\stackrel{\circ}{\circ}$ & 0 & 0 & 0 & 0 & 0 & $\circ$ & 0 & 0 & 0 & $\stackrel{\circ}{\circ}$ & $\stackrel{\circ}{\circ}$ & $\stackrel{\circ}{\circ}$ & 0 & 0 & o & 0 & 0 \\
\hline $\begin{array}{l}\frac{c}{n} \\
\frac{c}{c}\end{array}$ & $\frac{\underline{\alpha}}{\mathbf{L}}$ & & 0 & 0 & 0 & 0 & 0 & 0 & 0 & 0 & 0 & $\circ$ & 0 & 0 & 0 & 0 & 0 & $\circ$ & 0 & 0 & 0 & ○ & 0 & $\circ$ \\
\hline 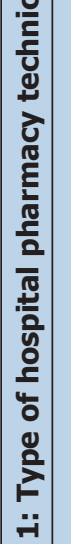 & & 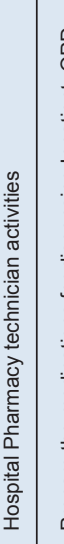 & 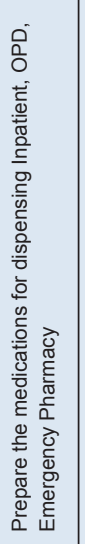 & 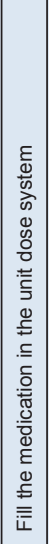 & 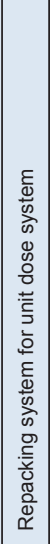 & 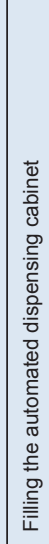 & 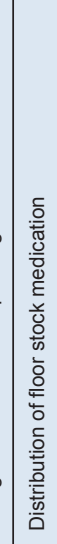 & 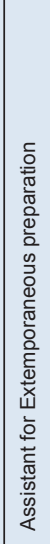 & 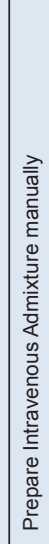 & 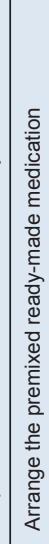 & 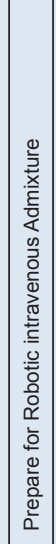 & 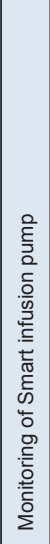 & 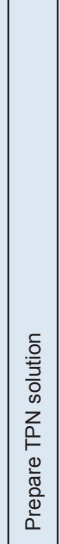 & 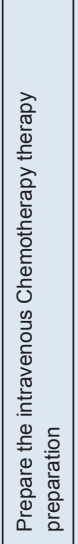 & 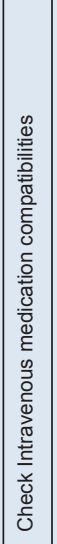 & 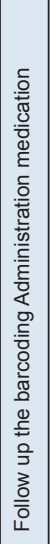 & 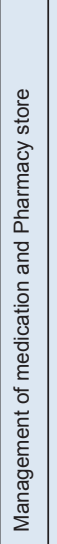 & 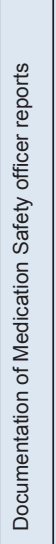 & 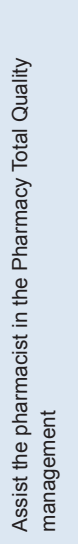 & 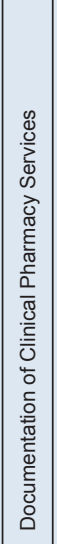 & 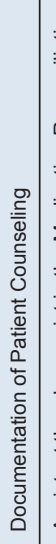 & 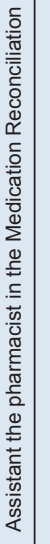 & 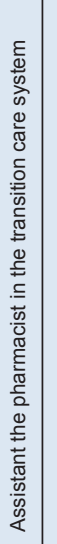 & 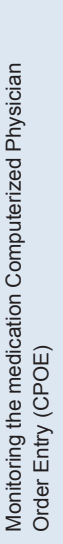 \\
\hline $\begin{array}{l}\frac{0}{0} \\
\frac{\pi}{5}\end{array}$ & & & - & $\sim$ & $m$ & $\nabla$ & ๑ & 0 & N & $\infty$ & 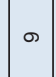 & $\div$ & $F$ & $\simeq$ & $\stackrel{m}{=}$ & 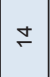 & $\stackrel{\curvearrowleft}{\sim}$ & $\div$ & 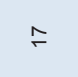 & $\stackrel{\infty}{\sim}$ & $\stackrel{9}{=}$ & 尺 & $\bar{N}$ & $\approx$ \\
\hline
\end{tabular}


$(1.07-5.02 \%)$ of all pilgrims with average (3.11\%). For the Ambulatory care, the average number of prescriptions was $(62,938)$, while $(13,674)$ was for an emergency prescription, and $(2,343)$ inpatient prescriptions. The mean number of ambulatory prescription per day $(2,349)$ contained $(7.047)$ medications, the emergency orders were (623) per day provided $(1,869)$ drugs, and Inpatient prescription was (108) per day included (324) medications as explored in table 1 . The total average number of pharmacy technician needed in Al-Madina was (69.2 FTE) per hospital. It divvied into (3.21FTE) for inpatient services per hospital, (11.48 FTE) for Emergency services per hospital, and (54.51FTE) for Ambulatory care services per hospital as explored in table 2. The average number of pharmacy technician calculated per hospital was (38.47 FTE), while the mean number pharmacy technician needed to base on workload for all services was (69.20 FTE) per hospital. It considered (1.8 fold) more incremental than $\mathrm{MOH}$ pharmacy technician workforce standards per bed with the new suggestion of workforces as the number of pharmacy technician per bed during mass gathering Hajj period was 0.42 as explored in table 3 . There were not any central pharmacy technician activities, clinical pharmacy technician services or administrative pharmacy technician activities.

\section{DISCUSSION}

The Ministry of Health started the health care strategic plan in 2010 with several achievements. ${ }^{[28]}$ The pharmacy strategic plan among them to cover more than 250 hospitals and 2000 primary care centers and all regions in the kingdom of Saudi Arabia with emphasis on Makka and Al-Madina regions. ${ }^{[2]}$ The pharmacy administration at $\mathrm{MOH}$ involved pharmacy technicians as membership into several central or peripheral committee including pharmacy total quality management, the computerized and pharmacy automation, and pharmacy public education committee. The pharmacy administration conducted several education courses including medication safety, pharmacy total quality management, and Intravenous admixture and Total parental nutrition with participated of pharmacy technicians from all regions including AlMadina region. Also, there were special courses during mass gathering hajj event either traditional or electronic courses. The pharmacy administration started a unique pharmacy technicians training program with new staff for six months with the collaboration of medical education and trading administration. The program formulated by international universities from United Kingdom (UK) and Canada and pharmacy administration with the educational department at $\mathrm{MOH}$. The program consisted of an essential

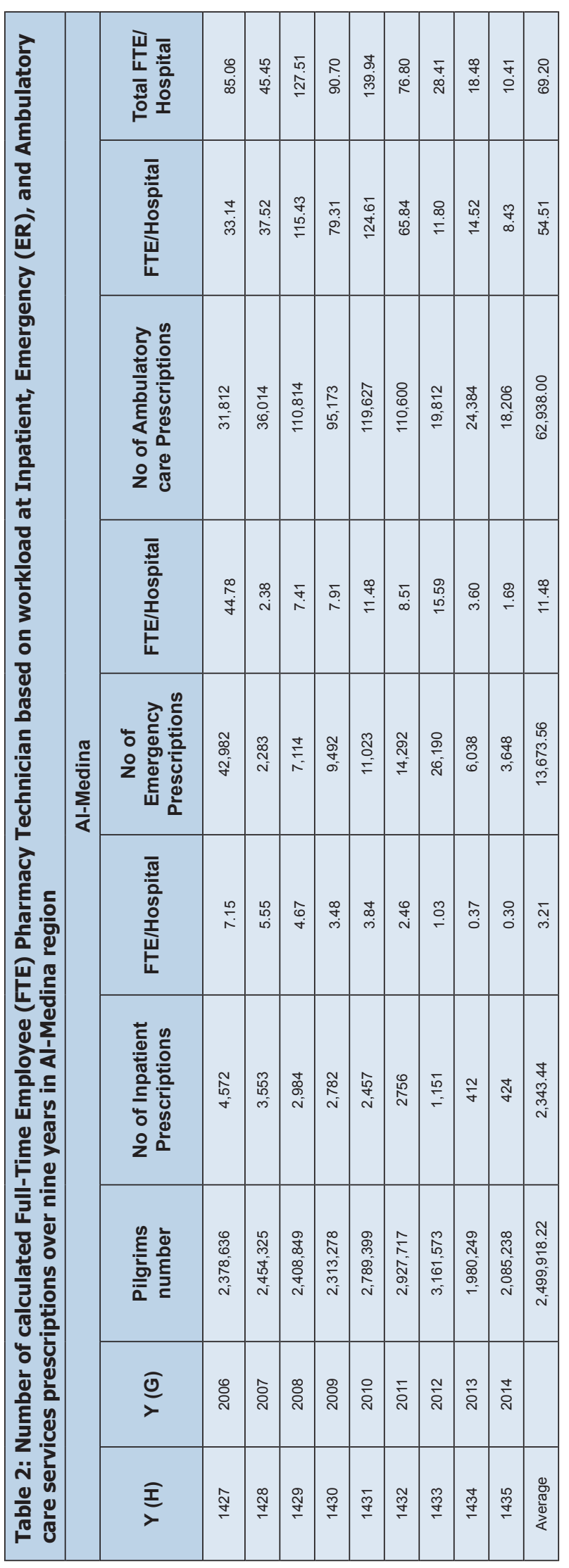




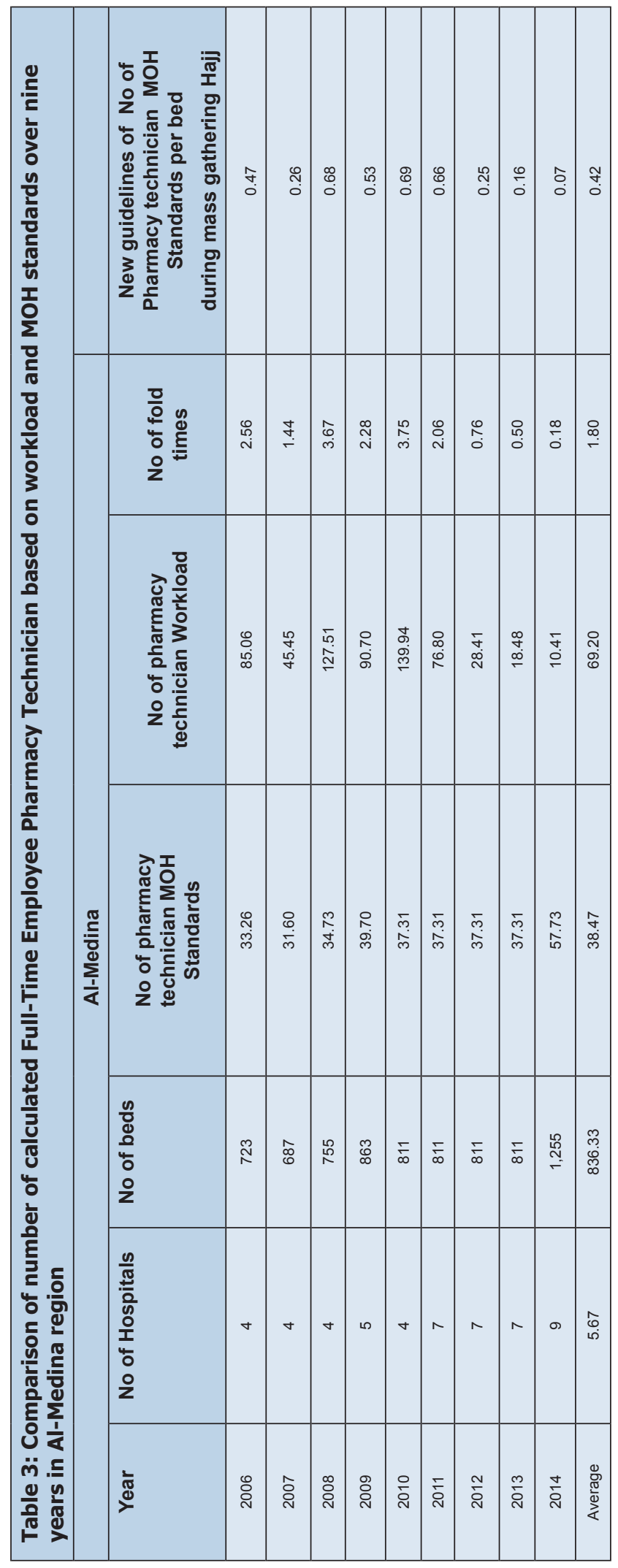

aspect of pharmacy practice with goals and infective for each unit, competency measuring and evaluating tools. All documented system was electronic through the website of $\mathrm{MOH}$. That covered all regions in the kingdom including Makka and Al-Madina regions. The authors try to investigate the demand for pharmacy technician's workforce during mass gathering hajj time with outcomes results reflect of pharmacy technician's performance with high percentages of preparation medication for also dispensing medication safety and quality management reporting. The other pharmacy technicians performances were weak. That is because implementation plan not completed conducted. The results finding with the very high demand for pharmacy technicians several times fold incremental during mass gathering hajj period as compared with regular days. The author suggested updating $\mathrm{MOH}$ standards of a pharmacy technician to be 0.42 per bed during mass gathering hajj period. After very extensive literature review an only small number of studies discussed utilized physician and nurses during mass gathering events but not pharmacy technician. ${ }^{[30-32]}$ The authors could not compare the results other studies. It seems the study was the first investigation conducted in the world. The study excluded the pharmacist and clinical pharmacist for further investigation shortly.

Limitation: Despite the study was the first overall the world there are certain restrictions included; the $\mathrm{MOH}$ statistical books not mentioned all pharmacy services included pharmacy technician workload during mass gathering Hajj period, a complete demographic data about hospital missed the in MOH database, and the pharmacy technician publication in Saudi Arabia missed.

Conclusion: The pharmacy technician workload reflected the demanding during mass gathering Hajj period in Al-Medina region, Saudi Arabia despite the missing of nonclinical and clinical pharmacy technician performances. Targeting of complete documentation of pharmacy technician related issues assist to refresh real calculation of pharmacy technician workforces calculation during mass gathering Haji period in the future's studies in Al-Medina region, Saudi Arabia.

\section{ACKNOWLEDGEMENT}

I want to thank all staff at Health affairs administration and pharmaceutical care administration in Al-Medina region for their cooperation. 


\section{CONFLICT OF INTEREST}

None

\section{ABBREVIATION USED}

KSA: Kingdom of Saudi Arabia, MOH: Ministry of Health, UK: United Kingdom

\section{REFERENCES}

1. World Health Organization. Public health for mass gathering: key considerations. 2015; Available from www.who.int/about/licensing/ copyright_form/en/index.html

2. Saudi Ministry of Health. Health Statistical Year Book 2016. Available from: http://www.moh.gov.sa/en/ministry/statistics/book/pages/default.aspx

3. Steffen R, Bouchama A, Johansson A, Dvorak J, Isla N, Smallwood C, et al. Non-communicable health risks during mass gatherings. Lancet Infect Dis. 2012;12(2):142-9.

4. Memish ZA. The Hajj: communicable and non-communicable health hazards and current guidance for pilgrims. Euro Surveill. 2010;15(39):19671.

5. Khan NA, Ishag AM, Ahmad MS, El-Sayed FM, Bachal ZA, Abbas TG. Pattern of medical diseases and determinants of prognosis of hospitalization during 2005 Muslim pilgrimage (Hajj) in a tertiary care hospital. A prospective cohort study. Saudi Med J. 2006;27(9):1373-80.

6. Alfelali M, Rashid H. Prevalence of influenza at Hajj: is it correlated with vaccine uptake? Infect Disord Drug Targets. 2014;14(3):213-8.

7. Al-Hoqail IA, Abdalla AM, Saeed AA, Al-Hamdan NA, Bahnassy AA. Pilgrims satisfaction with ambulatory health services in Makkah, 2008. J Family Community Med. 2010;17(3):135-40.

8. ASHP. Roles and Responsibilities of Pharmacy Technicians. Am J Heal Pharm. 2016;73:928-30.

9. National Association of Pharmacy Regulatory Authorities. Professional Competencies for Canadian Pharmacists at Entry to Practice. 2007. Available from: http://napra.ca/content_files/files/comp_for_cdn_ pharmacists_at_entrytopractice_march2014_b.pdf

10. The Society of Hospital Pharmacists of Australia. Exploring the role of hospital pharmacy technicians and assistants to enhance the delivery of patient centered care A White Paper on the findings and outcomes of the. 2016. Available from: http://shpa.org.au

11. Ahmed Alomi Y. National Mass Gathering Pharmaceutical Care Program at MOH in Saudi Arabia. J Pharm Pract Community Med. 2016;2(23):102-3.

12. Saudi Ministry of Health. Health Statistical Year Book 2007. Available from http://www.moh.gov.sa/en/Ministry/Statistics/book/flash/1428/ MOH_Report_1428.html

13. Saudi Ministry of Health. Health Statistical Year Book 2008. Available from: http://www.moh.gov.sa/en/Ministry/Statistics/book/flash/1429/ MOH_Report_1429.html
14. Saudi Ministry of Health. Health Statistical Year Book 2009. Available from http://www.moh.gov.sa/en/Ministry/Statistics/book/flash/1430/ MOH_Report_1430.html

15. Saudi Ministry of Health. Health Statistical Year Book 2010. Available from http://www.moh.gov.sa/en/Ministry/Statistics/book/Pages/default.aspx

16. Saudi Ministry of Health. Health Statistical Year Book 2011. Available from http://www.moh.gov.sa/en/Ministry/Statistics/book/Pages/default.aspx

17. Health Statistical Year Book 2012. Saudi Ministry of Health. Available from: http://www.moh.gov.sa/Ministry/Statistics/book/Documents/1433.pdf

18. Saudi Ministry of Health. Health Statistical Year Book 2013. Available from: http://www.moh.gov.sa/en/Ministry/Statistics/book/Pages/default.aspx

19. Saudi Ministry of Health. Health Statistical Year Book 2014. Available from: http://www.moh.gov.sa/en/Ministry/Statistics/book/Documents/StatisticalBook-for-the-Year-1435.pdf

20. Health Statistical Year Book 2015. Saudi Ministry of Health. 2015. Available from: http://www.moh.gov.sa/ministry/statistics/book/pages/default.aspx

21. Hospital OG. About the Hospital. Available from: http://ohudhospital.com/ cont/s/45

22. Al Ansaar General Hospital. Departments \& Services | Ansar Hospital. Available from: http://ansar-eedgroup.com/services/

23. Saudi Ministry of Health. Al Anasar Hospital Serviced more than Half Million Pilgrims. Available from: http://www.moh.gov.sa/Directorates/Madinah/ MediaCenter/News/Pages/Page_1435-02-16-007.aspx

24. Ministry of Health. MOH Publications - Madinah Health Affairs Directorate Intensifies its Preparations for Serving Pilgrims. Available from: http://www.moh.gov.sa/en/Ministry/MediaCenter/Publications/Pages/ Publications-2013-09-18-001.aspx

25. Bond C, Raehl C, Franke T. Clinical Pharmacy Services, Pharmacist Staffing, and Drug Costs in United States Hospitals. Pharmacotherapy. 1999;19(12):1354-62.

26. Bond C, Raehl C, Franke T. Total Cost of Care, and Length of Stay in United States Pharmacy Services and Staffing. Pharmacotherapy. 2001;21(2):129-41.

27. Bond CA, Raehl CL. Clinical pharmacy services, pharmacy staffing, and hospital mortality rates. Pharmacotherapy. 2007;27(4):481-93.

28. Ministry of Health. A Achievements 2013. 1st Ed. Available from: http:// sgsminsk.by/_/media/Global/Documents/Technical Documents/Technical Datasheets/SGS-PCA-SA-Datasheet SFDA-A4-EN-11-V2.pdf

29. Alomi YA, Alghamdi SJ, Alattyh RA. Strategic Plan of General Administration of Pharmaceutical Care at Ministry of Health in Saudi Arabia 2012-2022. J Pharm Pharm Sci. 2015;1(3):1-8.

30. Sanders Ab, Criss E, Stecki P, Meislin HWH, Raife J, Allen, et al. An analysis of medical care at mass gatherings. Ann Emerg Med. 1986;15(5):515-9.

31. Smith WP, Wessels V, Naicker D, Leuenberger E, Fuhri $P$, Wallis LA, et al. Development of a mass-gathering medical resource matrix for a developing world scenario. Prehosp Disaster Med. 2010;25(6):547-52.

32. Kollek D. An Introduction to Mass Gatherings. 2014; 1-16. Available from: http://www.ceep.ca/publications/Mass_Gatherings.pdf

Cite this article as: Alomi YA, Alhennawi K, Khayayt N. Pharmacy Technician Workload and Human Resources Requirements at MOH Hospitals During nine years mass Gathering Hajj (2006-2014) in Al-Medina Region, Saudi Arabia. J Pharm Pract Community Med. 2017;3(4s):S101-S106. 